Apis mellifica (bive bee) on the above bed confined itself to the mignonette. This remark applies to several individuals. Chester, August 17 AlfRed O. WALker

\section{A Meteor}

A BeAUTIFUr meteor was seen from this place on Sunday evening, August 19, at 10.3 precisely. Owing to the brilliancy of the moon, stars of the first magnitude were but faintly seen. I should say the size and brilliancy of the meteor was greatly in excess of the planet Venus at it: best. It was visible as far as I could conjecture about three seconds, and pursued a course of probably 45 or 50 degrees, proceeding from a point a few degrees to the eastward of, and higher than, the north star. It moved almost in a straight line downwards with an inclination to the left. When it had got about half of its whole visible course, it seemed to get blue in colour, and threw off a mass of red sparks, and continued for the rest of the distance, when it appeared to burst, and the disjected fragments were red and visible for a few moments. The colour for the most part was very much like that of Venus, indeed, for the whole of the course, except where it seemed to turn blue.

Lansdowne Road, Wimbledon, S.W., August 2 I

I SAW a very brilliant meteor from the promenade here last night (Sunday, August 19), at ro.3 p.m. It passed along the eastern sky and vanished over the summit of the Little Orme. The meteor was, I think, more brilliant than Venus at her brightest, though the full moon was shining not far off and very few stars were visible. The path was northward, nearly horizontal, inclined a little downwards, about $10^{\circ}$ or $12^{\circ}$ above the horizon, apparently much foreshortened, for the motion was very slow-not faster than that of balls falling from a rocket white light, slightly tinged with blue. The meteor divided, and left one large and I think several smaller portions behind it, all vanishing together. It should have been seen overhead towards the coast of Yorkshire.

Llandudno, August 20

\section{Animal Intelligence}

A CIRCUMSTANCE exceedingly illustrative of the sagacity of the horse was witnessed by myself in the neighbourhood of Nottingham. I had been out for a stroll by way of recreation, returning home across some fields by the Trent side, and when nearly opposite Clifton Grove I stopped a short time to watch a man angling in the river, when suddenly my attention was drawn to a mare with her foal, not many yards distant from where I was standing, open two gates which were vice versa, closing with a strong spring. Her modus operandi was to place her nose in between the two gates and force one gate open with her side, while she had no little difficulty in opening the other for the purpose of getting through. I have learnt that the animal had not been trained to do this, but taught by natural instinct, and so cleverly was it done that man could scarcely have performed the action better. Thinking this instance of sagacity wight be interesting to some of our naturalists, I take the liberty of forwarding same in order that you may insert it in your valuable paper.

9, Charlotte Street, Nottingham

F. WELCH

MR. H. Cecrl's communication respecting the cat and the chicken, at p. 320 of your present volume, reminds me of an instance of the attachment of a cat to its natural prey which is still more remarkable, as there was no "maternal stopy $\eta$ " in question.

Some years ago we had a young emasculated tom cat. When it was nearly full grown we had two young white rabbits brought in which had lost their mother. These were kept in the kitchen, and fed by pouring milk into their mouths with a spoon. They were placed in a basket at night and covered up to protect them from the cat, which was in the habit of catching wild rabbits. One morning the cover was found to have been removed by the cat, which was lying in the basket with the little rabbits. From that time he took charge of them, teaching them to lap milk and watching over them like a mother, even to the extent of driving them home when they grew older and rambled out from the kitchen. The friendship continued till the rabbits grew up, when we lost them by disease.

Chester, August I 7

\section{"Birds and Cholera"}

IN refererence to "H. M. C's." letter in this week's NATURE (p. 366), it is interesting to recall how the traveller Jackson, speaking of the playue that occurred in West Barbary when he was there, says, "The birds of the air fled away from the abodes of men." Thomas Moore, in "Paradise and the Peri," refers to this fact.

E. S. T.

August 18

\section{LIQUID FILMS AND MOLECULAR MAGNITUDES}

SIR WILLIAM THOMSON'S lecture on "The Size of Atoms," which has recently been published in NATURE, will undoubtedly increase the interest felt in measurements which throw any light upon the values of molecular magnitudes.

We have for some time been engaged in investigating the properties of very thin liquid films, and in our last communication to the Royal Society (of which only an abstract has been hitherto published, but which will appear in a forthcoming number of the Philosophical Transactions) we have described two independent methods by which we have obtained concordant measurements of the thickness of soap films in the last stage of tenuity, viz. when exhibiting the black of the first order of Newton's rings.

The paper had not been sent in to the Royal Society at the time when Sir Wm. Thomson's lecture was delivere I, but, on receiving the abstract, he has been good enough to express his approval of our methods and interest in our results, and to raise some questions as to the relation hetween the observations of Newton and ourselves, the further discussion of which he thinks would be interesting to the readers of NATURE.

We propose therefore briefly to discuss the facts which bear upon the points raised by Sir Wm. Thomson, and to describe our methods of experiment so far as may be necessary to make the discussion intelligible.

For thicknesses greater than those which correspond to colours of the first order, the tint displayed affords to a practised eye (when combined with a knowledge of the angle of incidence and refractive index) a very accurate measure of the thickness of a film. In some experiments of our own, in which on more than 500 occasions two independent but simultaneous measures were made of film-thicknesses by means of two beams of light, incident at different angles, we found that the two values obtained agreed to within i per cent. in 52 measures out of every hundred, to within 2 per cent. in 84 , and to within $3 \mathrm{per}$ cent. in 95. All these observations were made in the second and higher orders. The colours of the first order vary from point to point too slowly to enable trustworthy estimates of the thickness to be made, ard when the black of the first order is reached the eye informs us only that the thickness must be less than a certain value, but affords no further indications as to what it really is. The fact that it is extremely small, and the possibility that it may be related to the magnitude of the so-called "radius of molecular attraction," invest the problem of the determination of this thickness with special interest. We have succeeded in solving it by two methods. In each an assumption has to be made for which there is no direct experimental evidence. In each case, however, the assumption is different, and the fact that the mean results obtained by the two methods are in close accord is sufficient to show that, although there is still room for further inquiry, the mean thickness of the black soap films examined was correctly determined to within a fraction of a millionth of a millimetre.

The first method consisted in measuring the electrical resistance of a cylindrical black soap film, and deducing the thickness from Ohm's law, on the assumption that the 
specific resistance of the liquid, when drawn out into so thin a film, is the same as that determined under ordinary conditions.

We have, by direct experiment, proved that this assumption is true for films the thickness of which exceeds $374 \times 10^{-6} \mathrm{~mm}$. (Philosophical Transactions, 1881, p. 447). The investigation was considerably protracted by the great difficulty experienced in maintaining the constitution of the films even approximately constant. Every change in temperature, every slight alteration in the hygrometric state of the air in the glass chamber in which the bubbles were formed, involved a loss or gain of water which affected the specific resistance so largely as to make any certain conclusion impossible. It is only in our latest apparatus that we have secured the requisite constancy in the conditions. In it the films are formed in a chamber surrounded by water to keep the temperature constant. The base of the inclosed space is covered by the solution used, and the complete saturation of the air is further secured by an endless band of linen passing over rollers which can be worked from the outside. The lower roller is immersed in the solution employed, and thus every part of the linen can in turn be dipped into the liquid and kept completely saturated without opening the case. The films are blown as spherical bubbles with air which has been caused to pass over some of the liquid in order to insure saturation; they are converted from spheres into cylinders adhering to two rings, and are further put in communication at any desired point with the electrical apparatus without opening the case, and thus without affecting the temperature or saturation of the air with which they are in contact. A thermometer and a hair-hygrometer, placed in the closed chamber, serve to detect any change of conditions which these precautions fail to obviate.

The earlier form of apparatus described in our paper "On the Electrical Resistance of Thin Liquid Films" (Phil. Trans., loc. cit.), was in some respects less perfect. By it, however, we were able to show that the specific resistance of a film differed less and less from that of the liquid from which it was formed, as the temperature and hygrometric state of the air become more and more constant, and that in the case of the six films in which the desired constancy had been most successfully attained, the difference amounted only to I 8 per cent.

It was also shown that there was no indication of any change in the specific resistance between thicknesses corresponding to the middle of the red of the sixth and of the yellow of the second order respectively. As the smaller of these thicknesses is nearly the same as the wave-length of the rays which bound the spectrum at the blue end, this result may be roughly stated as proving that the thickness of a film may be reduced to the length of the shortest visible light wave without any change in the specific electrical resistance of the liquid of which it is composed.

In the course of some of our earlier experiments (Proc. Roy. Soc., 1877, p. 334) we had been fortunate enough to make a soap solution, giving very persistent films, which frequently thinned to the black of the first order. The resistance of the black portion was measured on several occasions, and it was found that the thickness was in all cases nearly the same (the variations amounted to about 5 per cent.), and differed but little (if the specific resistance was assumed equal to that of the liquid in mass) from 12 millionths of a millimetre $\left(12 \times 10^{-6} \mathrm{~mm}\right.$.).

We were anxious to try this experiment again with our improved apparatus and methods of measurement, but great difficulty was experienced in obtaining a liquid which would both thin and last sufficiently for our purpose. We have not, in fact, succeeded in again making a solution, containing the proportion of glycerine recommended by M. Plateau, which would behave in the desired way, but we find that a liquid of similar constitution, in which the glycerine is replaced by water, will allow a measurement of the resistance of the black to be made in the case of about one film out of every three or four.

Films which do not contain glycerine generally exhibit greater irregularities of behaviour than those which do, and thus our later experiments are not in as close agreement as the earlier ones. They indicate that, whereas the thickness of the black portion of a film remains constant however much its area may alter, it is different in different films. All the values obtained lay between $14.5 \times 10^{-6}$, and $7.2 \times 10^{-6} \mathrm{~mm}$., and the mean value $11^{7} 7 \times 10^{-6}$ differed only by two ten-millionths of a millimetre $\left(2 \times 10^{-7} \mathrm{~mm}\right.$.) from our previous result.

In spite of this close agreement these results were open to criticism. It is a long way, in terms of molecular magnitudes, from the yellow of the second to the black of the first order. We had no right to argue from results on the specific resistance at the greater thickness to its constancy at the less. It was, therefore, very important to attempt to check our observations by some independent method.

We had often observed that plane circular films formed in a glass tube thinned very readily to the black. This was perhaps due to the fact that the small aggregation of liquid all round the film affords a channel by means of which the liquid can readily escape. However this may be, it occurred to us that, though it was probably impossible to measure the thickness of a single black film by any optical method, it might nevertheless be possible to determine the total thickness of a number of parallel films in a tube. This we have succeeded in doing. The tube and its contents were placed on an apparatus for producing interference by thick plates. One of the interfering rays passed through the tube. A few steel sewing needles were included within it. When the films became black, a number of them were broken by moving the needles with a magnet, and the thickness could be calculated by observing the positions of the interference fringes before and after the rupture. By this method the mean thickness of the films was measured, on the assumption that the refractive index of the films was the same as that of the liquid in mass. Various considerations led to the conclusion that this was probably correct, but in any case the complete independence of the electrical and optical methods made each a valuable check on the other, though--if the fundamental assumption was correct-the former was by far the more accurate.

The result showed the two methods in most satisfactory accord. The mean of all the electrical observations gave a thickness of $11.8 \times 10^{-6} \mathrm{~mm}$., that of all the optical I I $4 \times 10^{-6} \mathrm{~mm}$., an agreement which places it beyond doubt that the mean value for all the films observed was really about $1 \mathrm{I} .6 \times 10^{-6} \mathrm{~mm}$.

The methods employed then afford a definite measure of thicknesses much smaller than the smallest that Newton's scale of colours allows us to estimate. That scale is very uncertain when colours of the first order are employed. The difficulty or impossibility of obtaining perfect contact between the lenses in the fundamental experiment, and the possible distortion of their form in the neighbourhood of the points of closest contact, make colour estimates of thickness in the first order very doubtful. The few observations we have made, on films exhibiting the red and orange of the first order, show a discordance with Newton's results in striking contrast to the agreement obtained in the case of most greater thicknesses.

Our estimate of the thickness of the middle of the red of the first order $\left(284 \times 10^{-6} \mathrm{~mm}\right.$.) differs from Newton's by 20 per cent. In the blue of the second order our own observations on Newton's rings differ from those on the soap films by 6 per cent., and we were obliged, when aiming at an accuracy of I per cent., to discard all observa- 
tions below the border of the yellow of the second order $\left(374 \times 10^{-6} \mathrm{~mm}\right.$. when the light is incident at $\left.45^{\circ}\right)$.

On the other hand, our electrical observations of a black film often give the same thickness to within $I$ or 2 per cent., again and again, in a series of observations extending over an hour or more.

This constancy may be taken as proving that the film is not absorbing nor losing moisture, and if its composition thus remains unaltered it is not too much to say that the electrical method extends to $7 \cdot 2 \times 10^{-6} \mathrm{~mm}$. (the smallest thickness measured by us), with an accuracy previously attainable only above $374 \times 10^{-6} \mathrm{~mm}$. In other words, it carries the accurate measure of thickness fifty times nearer molecular magnitudes than Newton's scale of colours does.

We now come to the interesting point raised by Sir William Thomson, which we may perhaps be allowed to state in his own words as follows :- "Newton, in the passage I have quoted (NATURE, vol. xxviii. p. 250), being Observation 17 of the Second Book, Part I., of his 'Optics,' says (I) he found in the large black spot smaller black 'round' spots which were blacker still ; (2) he saw sunlight reflected from even the small darker spots; (3) the black spots would break out in the middle of white, without any intervention of blue, and sometimes within the yellow or red or blue of second order. This (3) agrees with your (I) of p. I5I. But the (I) above of Newton's shows a higher grade of thinness than that of the main black spots, which I presume is that which you have found as $I \times 10^{-5}$. I do not know if you have noticed these smaller and blacker spots. It would be exceedingly interesting if possible to find their thickness, and to see how they seem to be related to the main black spots."

It may be well when answering this inquiry as to whether we have observed the smaller black spots, to state such facts as we have observed connected with the formation of the black.

In the first place we have noticed that the boundary between the film proper, and the small aggregation of liquid which connects it with the solids by which it is supported, is the place where, under ordinary circumstances, discontinuous spots, i.e. spots having a thickness different from that of the surrounding film, are most readily formed. The small circular masses of liquid which surrounded the gold wires by which the film was connected with the electrometer were sometimes themselves surrounded by a very narrow ring, showing the white of the first order when all the film immediately outside it was much thicker. Small specks of white would frequently break off from the topmost point of this ring, and either rise through the film to its highest point, or if, as was often the case, the liquid of the film was in a state of internal motion, the white flecks would be carried round the cylinder in spiral paths. Some liquids almost invariably gave films which, shortly before rupture, became thus covered with white flecks. Occasionally a white band, several tenths of a millimetre in breadth, was formed all round the upper ring which carried the cylindrical film, when the portion of film next it showed colours of the second and higher orders, and it was owing (among other reasons) to the frequent presence of this ring that we abandoned the Wheatstone's bridge method used in our first experiments (Proc. Roy. Soc. 1877, p. 334), and adopted the electrometer method which we now always employ. The necessity of having to make an allowance for the resistance of the white ring, the thickness of which was much more uncertain than that of the coloured portion was thus avoided. We may remark that irregularities of all kinds are more likely to occur if all parts of the apparatus are not frequently and scrupulously cleaned. We have also examined the lines of discontinuity between the black and the coloured portions, using a microscope with a three-inch object glass. In many cases the discontinuity was seen to be only apparent. Bands of colour were visible, which proved that the missing tints were really there, but on so small a scale as to be invisible to the naked eye.

The phenomenon of the white band was sometimes still further complicated by the presence of spots in the white, differing in colour both from it and the film next it. Thus on one occasion when the colour next the white was the green of the fourth order (mean thickness $893 \times 10^{-6} \mathrm{~mm}$.) we made the following remarks in our notebook:- "At the top a narrow film of white was observed between the green and the solid cylinder. In this, small pieces of deep blue were moving slowly backwards and forwards. The lower part of the white was marked by two small rings of colour, so narrow that the colours were indistinguishable." Later on, the green at

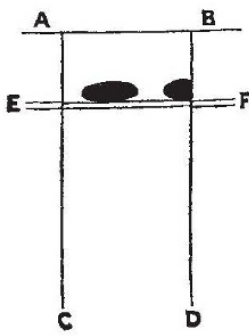

FIG. I.

one point broke through the white and completed contact with the top. This contact was in turn broken, and, after a while, the white appeared continuous without spots or bridges. A rough, highly enlarged sketch of the spots was made at the time, of which Fig. I is a copy.

$A B$ is the lower edge of the platinum cup which supports the film. A C and B D are the boundaries of the bright line produced by the light thrown upon the film at a known angle for the purpose of measuring its thickness. EF is the edge of the white. Two of the blue spots which appeared to float in it are shown, and the narrow line of colour is indicated. Below $\mathrm{E} \mathrm{F}$ the thickness was about nine times greater than that in the white space above it.

Our reason for describing this observation at length is to draw attention to the curious phenomenon of the blue spots separated by an apparent discontinuity from both

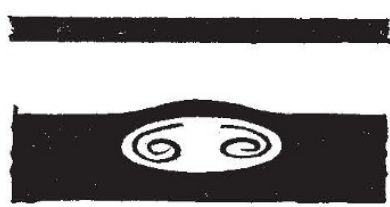

FIG. 2

the white and the green. From the green they were no doubt separated by a thin line of white, and through this frail band, perhaps a few hundredths of a millimetre broad and one ten-thousandth of a millimetre thick, they were unable to sink into the green below.

In the same way white flecks have been observed to rise and to be separated for some seconds from the white ring above by a thin band of colour. Such flecks, examined by the microscope, sometimes show colours of higher orders within them, arranged in curves owing to a regular vortical circulation. The appended sketch (Fig. 2), drawn from memory, gives some idea of the appearance displayed, the size being of course greatly exaggerated.

Turning now from the formation of the white to that of the black, many of the phenomena observed in the 
case of the cylindrical films are closely similar. Specks of black also readily form in the neighbourhood of the solid in contact with the film. They, too, rise through the surrounding liquid, and the growth of the black ring at the top of the film is sometimes caused as much by additions of black spots from below as by a downward motion of the lower edge. These phenomena are only observed on a large scale shortly before the rupture of the film.

The black appears at times in other ways. Sometimes when the white of the first order was in contact with and below the black, a small portion of it would rapidly disintegrate. It would become streaked with black lines, the white portions would fall down through the rifts thus formed, and a sudden extension of the black would thus take place. In films containing smali quantities of glycerine this phenomenon is sometimes observed on a very large scale.

There is also a third way in which the black appears, namely, in cases where there is no discontinuity between the white and black. Here the thinning takes place in the normal way, but, as in Newton's observations, specks of a deeper black frequently appear. This phenomenon may easily be sbown as a lecture experiment. If a few drops of water be placed on the surface of a piece of yellow soap, and the end of a glass tube ground plane be dipped into them, a film can be removed. On throwing a magnified image of this on the wall, it is observed to thin rapidly. The white often passes through gray into black, and then the deeper black spots appear and rise to the top of the film. Within our experience, however, this phenomenon occurs only in the case of transient films formed of a liquid which does not allow any high degree of persistence. It is for this reason that in the summary of results with which we conclude our paper, and which is given in the abstract (see NATURE, vol. xxviii. p. I42), we limit our statements to "persistent soap films." It is on these only that we have been able to make measurements, and of these only that we have any certain knowledge.

While, therefore, in answer to Sir Wm. Thomson, we are able to say that we have often observed the same phenomenon as Newton, viz. that of a deeper black separated by a line of apparent discontinuity from the less intense black which surrounds it, this observation has only been made in the case of liquids like that used by Newton, which he describes as "water made tenacious by dis. solving a little soap in it."

We have made use of two liquids in the experiments on which our published results are based. In the case of the "liquide glycérique" the black was under continual inspection, the colours of the remainder of the film being frequently noted during the experiments, and when the film became very thin and uniform in colour, the observer had plenty of time to study its appearance. We have no recollection of ever having observed any black specks deeper than that of the main mass of black, either stationary, or moving about in it. Had they been formet in large quantity, our electrical measurements must have detected them. They would have risen through the thicker black as the white or black specks do through the coloured parts of the films, and would have congregated in the upper part and formed a ring of greater tenuity at the top. If, as analogy would lead us to suppose likely, they had appeared in greatest quantity towards the end of the film's existence, the resistance of the black area would have increased more rapidly than its length. We tested this by grouping our experiments according to the length of the black area (Proc. Roy. Soc., June $21, \mathrm{~J} 877$, p. 344), and found that the resistance per millimetre was, to within the limits of the errors of experiment, constant, whether the black was less than two or more than ten millimetres in length.

The second liquid, which was formed only of oleate of soda and water, was more similar to Newton's and more likely to give similar results. With this we could obtain such large areas of black that the electrometer method enabled us to measure the resistance of a portion of the black alone, without regard to that of the coloured portions of the films. These films were therefore observed much less closely than those formed of "liquide glycérique," but no eye observation or electrical measurement ever gave any indication of more than a single thickness of the black for each particular film.

Coming now to the optical observations, we have indeed noticed in the earlier stages of the history of the black films a bending of the interference fringes in the lower parts of the black region, which might indicate that near the coloured part of the film it was somewhat thicker than at some distance from it. It is, however, very doubtful whether in this part of the field the light was passing through black films only. The area of the black was not exactly the same for all the fifty or sixty films inclosed in the tube, and thus near the boundary of the black the light might pass through a few white films, which would account for the apparent thickening. We were unable to satisfy ourselves as to which of these explanations is the true one, though the latter is the more probable. The question is fully discussed in our paper, in which we show that if the apparent thickening were really in the black, that colour must begin to show itself at a far greater thickness than that ordinarily assigned to the "beginning of the black," which is unlikely, though not, in view of the great uncertainty which attaches to this part of Newton's scale, impossible.

On the whole, then, we incline to the opinion that the number given by our experiments is the least thickness of the black in the liquids we observed. We also think that the tint our persistent films displayed is decidedly deeper than that of the less intense black shown by comparatively non-persistent films, though to make certain of this would require careful comparative observations. It is possible that the spots of deeper black in non-persistent films may be thinner than that we have measured, and the very fragility of the films in which they appear gives some colour to the supposition that it is so. It is, however, significant that, in two liquids differing so much in composition as those we employed, the one containing two parts of glycerine out of five, and the other no glycerine at all, the means of the optical and electrical measurements give results differing so little as $\mathrm{I} I \mathrm{I} 3 \times 10^{-6}$ and $11.9 \times 10^{-6} \mathrm{~mm}$. It would be very interesting to settle the question by direct experiment, but the nature of the films which show the two kinds of black would make it no less difficult. We are, however, at present studying the composition of what we may perhaps call blackforming liquids in the hope of extending our investigations further, and if we can obtain one suitable for the purpose we will certainly attempt the measurement suggested by Sir William Thomson.

In conclusion we may point out two deductions from our measurements. The first refers to their connection with the subject of Sir William Thomson's lecture. If the size of the molecules of which the liquid is composed is between $2 \times 10^{-6}$ and $1 \times 10^{-8} \mathrm{~mm}$. (the limits given by him), it follows that the thinnest film measured by us, which was $7.2 \times 10^{-6} \mathrm{~mm}$., must contain not less than three and not more than 720 molecules in its thickness. The smallness of the smaller of these numbers tends to show that the real size of the molecules is considerably below Sir W. Thomson's superior limit.

The second deduction is a good illustration of the magnitude of the stress in a liquid surface, The surface tension of Plateau's "liquide glycérique" is about fiftyseven dynes per linear centimetre (cf. "Statique des
Liquides," t. i. p. 200). This force must not be considered as acting on a mathematical line, but as the resultant of forces which are in play in the thin layer of liquid which 
constitutes the surface, the thickness of which is the socalled radius of molecular attraction. If the magnitude of that radius were known, the average longitudinal tension per unit of area parallel to the surface in the outer layer of liquid could be calculated. We hope before long to apply several tests as to whether the thickness of a black soap film is or is not less than twice the radius of molecular attraction. Various considerations, the discussion of which we defer, indicate that it is not much less, while if the size of an atom approaches Sir William Thomson's lower limit it is probably much greater. If, however, we assume that the thickness of the thinnest film measured by us, say $7 \cdot 2 \times 10^{-7} \mathrm{~cm}$, was just equal to twice the radius of molecular attraction, it follows that the average stress parallel to the surface must be $2 \times 57 / 7^{\circ} 2 \times 10^{-7}=1 \cdot 6 \times 10^{8}$ dynes per square centimetre. This tension is eight times greater than that required to tear brick or cement asunder (cf. Everett's "Units and Physical Constants," p. 56), and one-half of that required to tear cast tin. If the radius of molecular attraction is the same for all substances, the stress in the surface of mercury in contact with air must be nearly ten times greater than in liquide glycérique, or one-fifth of the tension required to rupture steel bars. If the radius is less than half the thickness of the black films, these tensions would be greater.

In many of the ordinary calculations on capillarity the surface tension is treated as acting in a surface of infinite tenuity. In reality it acts in the matter of a liquid shell of small but definite thickness. Our experiments prove that the average magnitude of the stress in this shell is at least of the same order as that required to rupture the less tenacious metals.

A. W. REINOLD

A. W. RÜCKER

\section{JAPANESE LEARNED SOCIETIES}

NEARLY two years ago we described in NATURF a few of the principal of the scientific and learned organisations which had sprung up in recent years in Japan, in imitation of the societies of western countries. The faculty for combination and organisation would appear to be possessed in a high degree by the Japanese, for on all hands we find them establishing societies for political, self-help, philanthropic, industrial, commercial, scientific, and literary purposes. The comparative infancy of the press, and the consequent slowness and difficulty of the interchange of ideas, have rendered these organisations of great value in the social and political life of the country. The extent to which they have spread into every department of national life is well shown by a paper recently contributed by Herr P. Mayet to the Transactions of the German Asiatic Society of Fapan, to which we are indebted for most of the facts in this article. Societies for philantbropic and political purposes, though probably more numerous and powerful than any others, are entirely omitted as beside the present purpose, which is to show how the thirst for knowledge and research is penetrating everywhere amongst this interesting people. It is important, too, to note that these societies are everywhere fostered and promoted by the leading men of the country, including most of the Imperial princes and the Ministers of State, and that they appear to be due in all cases except one to native initiation, unassisted by foreigners. The exception is the Seismo logical Society, which owes its existence and its excellent work to the efforts of Prof. Milne of the Engineering College of 'Tokio. Recently, as we learn from Herr Mayet, a Japanese section of this society has been formed, with numerous native members, papers in Japanese, and a native journal containing original as well as translated contributions. Three of the societies at present in existence have come down from ancient times. These are the Numismatic and Archæological Societies, and an association of $G$ o players, similar to our own chess clubs. A society for the protection and restoration of ancient buildings, nearly all of which are naturally temples, has recently been founded, with the energetic support of the present Foreign Minister. As might have been expectef, there is a society for the cultivation of Chinese literature; but the more practical spirit of Young Japan is exhibited in the association for propagating the employment of the kana or syllabaries in Japanese literature. The importance of the object of this society will be evident when it is mentioned that a Japanese boy of the scholarly class takes from five to seven years to learn the sounds of the Chinese characters, and then he has to commence to learn their meaning. Herr Mayet well observes that so long as the Japanese youth are so heavily handicapped in the race for knowledge they can hardly hope for victory against western lads, who, according to this writer's estimate, are at twelve years of age nearly six years in advance of the Japanese boy of the same age. To remove this obstacle by the employment of the system of forty-seven syllables, now in use in books intended for the common people, is the object of this society, which has for president the Vice Finance Minister. Passing over some art societies, we come to two intended for the cultivation of the French and German languages respectively. One of these is honoured by the support of an Imperial prince. The French Society is working on a French-Japanese dictionary, while both aim at the publication of translations from useful works in these languages. Those hitherto published appear to deal chiefly with political science, a study which appears to attract much of the energy and intellect of the rising generation. A Statistical Society appears also to be very successful, with its periodical publication. The Polytechnic Association has for its object the extension of knowledge with regard to mechanical inventions, and their application to the increase of production in Japan. Agricultural, dendrological, and forestry societies are also in existence, and we may specially note, as a result of the recent Fisheries Exhibition in Berlin, the establishment of a society for the study and improvement of the Japanese fisheries. Many of these associations are, it will be observed, exceedingly practical in their aims, and if the members can succeed in having their discussions and researches circulated among the people, much good will undoubtedly result. The Geographical Society of Tokio has been frequently mentioned in these columns, but there is also a Biological Society under the presidency of the native Professor of Zoology in the University of Tokio. Medical societies also are numerous, whether for purposes of study or to afford aid and relief to the indigent sick. The society for the collection and publication of books with regard to domestic industries must be of much public utility. Of a more purely scientific cast is the association for publishing a dictionary of technical terms in various departments of science and the mechanical arts. The process of finding these termini technici is far from an easy one. They have to be obtained from the Chinese, and have frequently, perhaps generally, to be manufactured by combinations of the Chinese ideographic signs, which often have but a strained or fancied resemblance to the object to be named.

In concluding his paper Herr Mayet says: "Our glance at the Japanese societies of Tokio exhibits a wealth of active ideal life and earnest endeavour. A warm patriotic pulsation is perceptible everywhere, and gives an assurance of the healthiness of the Japanese popular mind. We have here, it is true, only the beginning of association, but it promises much, and the movement will undoubtedly be a constantly growing one." After all, however, the ultimate value of any learned society is measured by the work which it has done, and we have as yet but little opportunity of applying this test to the associations of Japan. 